\title{
Efficacy of Low Dose Topiramate and Propranolol in Migraine Prophylaxis
}

\author{
Khan MAM ${ }^{1}$, Ferdous ${ }^{2}$, Kabir AKMG ${ }^{3}$, Rashid MM" ${ }^{4}$ Islam MEU ${ }^{5}$, Khan SMD ${ }^{6}$
}

Conflict of Interest: None

Received: $20-10-2017$

Accepted: $19-11-2017$

www.banglajol.info/index.php/JSSMC
Key words:

Efficacy, low-dose

Topiramate, Propranolol,

Migraine

\begin{abstract}
Background: Migraine, the second most common cause of headache that can significantly impair the lives of people. Various drugs are available for migraine prophylaxis but all of which have varying degrees of adverse effects that may significantly limit their use.

Objectives: To observe whether low dose topiramate is more effective compared to propranolol in migraine prophylaxis.

Methods: Total 120 patients the age range of 18 to 50 years were recruited as study population of migraine in the Out Patient Department (OPD) \& Headache Clinic, BSMMU.60 patients were administered by Tab.Topiramate $50 \mathrm{mg} /$ day named as group-I and rest of 60 patients were administered by Tab. Propranolol $80 \mathrm{mg}$ /day named as group-II. Out of them in total 96 patients had completed the study. 47 patients had completed study in group-I and 49 patients in group-II. During trial, three follow up visits were taken for both groups, $1^{\text {st }}$ follow up after 4 weeks of baseline information, $2^{\text {nd }}$ follow up after 4 weeks of treatment, $3^{\text {rd }}$ follow up after 8 weeks of treatment. Efficacy of treatment was measured by frequency, duration and severity of headache as measured by the visual analogue scale (VAS).

Results: The mean (SD) age of group-I (topiramate) and group-II (propranolol) group were found $29.72 \pm 9.58$ years and $30.96 \pm 10.11$ years respectively. Female sex was found predominant in both groups. At final follow up, there was statistically significant difference in mean (SD) value of frequency of migraine between topiramate and propranolol group (4.72 $\pm 2.80 \mathrm{vs}$. $3.48 \pm 2.20 ; p=0.024]$. Propranolol appeared statistically significant than topiramate [TPM $5.53 \pm 2.98$ vs. PRO 4.36 $\pm 1.55 ; p=0.047]$. Regarding severity of headache, better results also were observed in the propranolol group than topiramate $(p<0.05)$. Both drugs appeared significant in efficacy measurement $(p<0.001)$. Patient drop out was more in the topiramate group than the propranolol group (21.68\% vs. 18.34\%). Furthermore, in the topiramate group, patients complained of more adverse effects than propranolol group (23.4\% vs. $14.3 \%)$, which was statistically significant.
\end{abstract}

Conclusion: The present study suggests that low dose topiramate and propranolol are effective for migraine prophylaxis in reduction of frequency, severity and duration of migraine individually and propranolol appears more effective compared to that of topiramate.

[J Shaheed Suhrawardy Med Coll 2017; 9(2): 49-54] DOI: http://dx.doi.org/10.3329/jssmc.v9i2.37262
1. Dr. Muhammad Abdul Momen Khan, Assistant Professor, Department of Neurology, National Institute of Neurosciences \& Hospital, Dhaka

2. Dr. Jannatul Ferdous, Resident, Department of Paediatrics, SSMC \& Mitford Hospital,Dhaka

3. Dr. AKM Golam Kabir, Associate Professor, Department of Radiology \& Imaging, National Institute of Neurosciences \& Hospital, Dhaka

4. Dr. Md Mamnur Rashid, Resident Physician, National Institute of Neurosciences \& Hospital, Dhaka

5. Dr. Md Enayet-ul- Islam, Registrar, Department of Neurology, National Institute of Neurosciences \& Hospital, Dhaka

6. Dr. S.M. Dastegir Khan, Medical officer, Department of Microbiology, SSMC \& Mitford Hospital, Dhaka

Corrospondence : Dr.Muhammad Abdul Momen Khan, Assistant Professor, Department of Neurology, National Institute of Neurosciences \& Hospital, Dhaka E-mail: momen37cmc@gmail.com; Cell no: +8801718738141

\section{Introduction}

Background

Migraine is an episodic central nervous system disorder characterized by vascular headache associated with vasodilatation of extra-cranial vessels but may be due to disturbed neuronal activity in the hypothalamus ${ }^{1}$. Migraine headache ranges from moderate to very severe in intensity and lasts from 4 to 72 hours ${ }^{2}$, often accompanied by photophobia, phonophobia and vomiting $^{3}$.

According to World Health Organization (WHO) migraine is the global burden of health related issue that study was conducted in 2000 and reported in the World Health Report 
2001.Migraine included for the first time in years lived with disability (YLD) \& contributing $1.4 \%$ of YLD, is the $19^{\text {th }}$ cause of disability in both sexes of all ages $\& 12^{\text {th }}$ in case of women, accounting for $2.0 \%$ of YLD ${ }^{4}$. Successful management of migraine requires intensive patient's educations and through physician knowledge about available treatment options and strategies ${ }^{5}$.

Migraine is a common condition, annually affecting $12 \%$ of the United States population, including $18 \%$ of women, $6 \%$ of men and $4 \%$ of children. Migraine is generally more common in people who are in lower socioeconomic groups ${ }^{6}$.

In Bangladesh there is no data regarding the prevalence of migraine. In a study conducted in BSMMU headache clinic total 3440 of headache patients were studied and $16.05 \%$ of them had a diagnosis of migraine ${ }^{7}$.

Different elements need to be considered in migraine management. They include avoidance of triggering factors, lifestyle modifications, non-pharmacological therapies and lastly medications. Pharmacological treatment is traditionally divided into acute treatment, and preventive treatment. Many migraine patients can be treated using only acute treatment that is used only during headache attacks to abort an ongoing attack. Patients with severe and/or frequent migraines require long-term preventive therapy ${ }^{8}$.

Prophylaxis is recommended to reduce the frequency and/ or intensity of migraine when patients experience more than three to five attacks per month. A variety of drugs are in use for migraine prevention. Adrenergic receptor blockers (e.g. propranolol), tricyclic antidepressants (e.g. amitriptyline), anticonvulsants (e.g. topiramate and valproate), and serotonergic drugs (e.g. methysergide) are most commonly administered for this purpose, as summarized in US Headache Consortium Guidelines. Topiramate showed statistically significant efficacy in migraine prevention. Among several treatment-emergent adverse events dose dependent weight loss is common. For these reason, slow titration of target dose of topiramate is advisable ${ }^{9}$.

Propranolol has been prescribed for migraine prophylaxis since 1966. The usual propranolol doses for migraine prevention from 80 to $160 \mathrm{mg}$ a day ${ }^{10}$. In a clinical trial comparing the efficacy of propranolol with sodium valproate in migraine prophylaxis in BSMMU showed that $53.17 \%$ decline in headache frequency, $64.81 \%$ decline in headache duration $\& 15.16 \%$ decline in headache severity, whereas $48.98 \%$ decline in headache frequency, $62.84 \%$ decline in headache duration \& $18.15 \%$ decline in headache severity ${ }^{11}$.
Propranolol has already been established itself as a comparator drug. Physicians are on the hunt for an alternative drug which might be superior to propranolol in efficacy or having at least same efficacy but can be used in situations where propranolol is contraindicated. For the last few years, high dose (100-200 mg/day) topiramate was used in migraine prophylaxis, but with such high doses, usually significant side effect could have occurred. ${ }^{12}$

In this context, the present study was designed to observe the effect of low dose topiramate $(50 \mathrm{mg} /$ day) in migraine prophylaxis comparing it with propranolol $(80 \mathrm{mg} /$ day $)$ in respect of efficacy, adverse effect $\&$ to see superiority or equality among Bangladeshi population.

\section{Materials and Methods}

This clinical trial was conducted in Out Patient Department (OPD) \& Headache Clinic, Department of Neurology, BSMMU, Dhaka, From July 2013 to June 2015. Informed written consent was taken from all patients. Migraine was diagnosed according to the criteria of the Headache Classification Committee of the International Headache Society, 2013(ICHD-3). Considering 10\% drop out in every follow up, sample size was 120 by using $N=16 /(E / S)^{2}$ formula. A total 120 patients were selected according to selection criteria.

\section{Inclusion criteria}

1. Patient of migraine (with typical aura or without aura) according to ICHD-3 criteria.

2. Age at entry: 18-50 years.

3. Patients not on any prophylactic medication.

4. Patients willing to take part in the study.

5. Patient being able to fill a headache diary successfully \& reliably.

\section{Exclusion criteria}

1. Age $<18$ years or $>50$ years.

2. Patients having headache other than migraine.

3. Patients on prophylactic medication.

4. Any co-morbidity such as heart failure, hepatic or renal impairment, diabetes, bronchial asthma, malignancy, intracranial vascular aneurysm, pregnancy \& breastfeeding etc.

5. Patients not willing to take part in the study.

6. Patient having known hypersensitivity to topiramate or propranolol.

Detailed history, general examination, neurological examination, routine laboratory investigations and other relevant investigations was carried out according to need. They were taught to maintain their headache character on 
a headache diary supplied to them \& advised them to report at the headache clinic after 4 weeks. Intensity of headache was measured by Visual Analogue Scale (VAS). VAS is graded as mild, moderate and severe in intensity.

Analysis was done by comparing the number of days (duration) with headache, frequency and intensity of headache according to visual analogue pain scale before starting of prophylaxis and that of 4 weeks and 8 weeks after treatment. Outcome measured were reduction of visual analogue pain scale score, duration and frequency of acute attacks of headache compared to the baseline with subsequent follow up, adverse effects were individually registered.The trial evolved into 2 stages:

Stage-1(4weeks): The base line period or medication ( topiramate/propranolol) free period. During this period the subjects were taught to fill their headache diary to record the baseline headache characters. Those who filled the headache diary reliably entered into the stage-2.Odd number patients are marked as group-1 \& even number patients are marked as group-II by lottery.

Stage- 2(8 weeks): Tab. Topiramate was given in group-I $\&$ Tab. Propranolol in group-II. The headache character was recorded by the patients themselves on headache diary. Continuous data were expressed as mean and standard deviation and qualitative data were expressed as frequency distribution and percentage. Statistical analysis was performed by using SPSS-21. Data were analyzed by Wilcoxon signed ranks test as data shows asymmetric distribution. For all statistical tests, we considered $p$ value $<0.05$ as statistically significant. Approval from the IRB of BSMMU was obtained prior to the commencement of this study.

\section{Results}

Total 120 patients in the age range of 18 to 50 years diagnosed as migraine (with aura or without aura) according to ICHD-3 criteria, were recruited as study population. Total 96 patients were completed the study due to drop out of 13 patients in group-I \& 11 patients in group-II in different steps of follow up. Table-I shows in group-I, $72.3 \%$ was female and $27.7 \%$ male. In group-II, $61.2 \%$ was female and $38.8 \%$ male. No statistically significant difference was observed between groups in terms of gender $(\mathrm{P}>0.05)$. Table-II shows ages ranged from 18-48 years (mean 29.72) in group-I \& in group-II ages ranged from 18-49 years (mean 30.96). A good number of the study patients were in 18- 25 year of age in both groups (42.6\% vs. $42.9 \%$ ). This table shows no significant difference in age distribution between group-I \& group-II. Table-III shows $16(16.7 \%)$ patients had migraine with aura. Among them, 7 patients in group-I and 9 patients in group-
II experienced aura. There was no statistical significant difference between group-I and group-II considering migraine with aura.

Table I

\begin{tabular}{lccc} 
& \multicolumn{3}{c}{ Study population by gender } \\
Gender & \multicolumn{2}{c}{ Type of Patients } & p-value* \\
& Group- I $(\mathrm{n}=47)$ & Group- II $(\mathrm{n}=49)$ & \\
\hline Female & $34(72.3 \%)$ & $30(61.2 \%)$ & \\
Male & $13(27.7 \%)$ & $19(38.8 \%)$ & $0.284^{\mathrm{ns}}$ \\
\hline
\end{tabular}

ns = non significant

*Chi square test was done to measure the level of significance

Table II

Study population by age

\begin{tabular}{lccc} 
Age (year) & \multicolumn{2}{c}{ Type of Patients } & p-value \\
& Group- I $(\mathrm{n}=47)$ & Group- II $(\mathrm{n}=49)$ & \\
\hline $18-25$ & $20(42.6 \%)$ & $21(42.9 \%)$ & $0.475^{\mathrm{ns}}$ \\
$26-35$ & $12(25.5 \%)$ & $8(16.3 \%)$ & \\
$36-45$ & $8(17.0 \%)$ & $14(28.6 \%)$ & \\
$46-50$ & $7(14.9 \%)$ & $6(12.2 \%)$ & \\
\hline
\end{tabular}

Mean (SD) [yrs $] \quad 29.72 \pm 9.58 \% \quad 30.96 \pm 0.11 \% 0.540^{\mathrm{ns} * *}$

Range (min-max) [yrs] (18-48) (18-49)

ns $=$ non-significant

*Chi- square test was done to measure the level of significance ** p- value was derived from Mann-Whitney U test

\section{Table III}

Aura of migraine among study population

\begin{tabular}{lccc} 
Type of Migraine & \multicolumn{2}{c}{ Type of Patients } & p- value* \\
& $\begin{array}{c}\text { Group- I } \\
(\mathrm{n}=47)\end{array}$ & $\begin{array}{c}\text { Group- II } \\
(\mathrm{n}=49)\end{array}$ & \\
\hline With aura & $7(14.9 \%)$ & $9(18.4 \%)$ & $0.648^{\mathrm{ns}}$ \\
Without aura & $40(85.1 \%)$ & $40(81.6 \%)$ & \\
\hline
\end{tabular}

$\mathrm{ns}=$ non-significant

*p- value derived from chi-square test.

Table-IV shows that mean (SD) value of frequency of migraine attack was found 9.28 (2.39) in group-I and that of 9.29 (2.46) in group-II. During $1^{\text {st }}$ follow up, nonsignificant differences in frequency of migraine attack were observed but there was more decreasing value in patients 
of group-II than that of group-I .During $2^{\text {nd }}$ follow up, there was statistically significant difference $(p=0.024)$ was observed in frequency of migraine attack between groupI and group-II.

\section{Table IV}

Frequency of migraine attacks in both groups

\begin{tabular}{lccc}
$\begin{array}{l}\text { Frequency of } \\
\text { Migraine attack }\end{array}$ & \multicolumn{2}{c}{ Type of patientsp -* } \\
& $\begin{array}{c}\text { Group-I } \\
(\mathrm{n}=47) \\
\text { Mean (SD) }\end{array}$ & $\begin{array}{c}\text { Group-II } \\
(\mathrm{n}=49)\end{array}$ & value $(\mathrm{SD})$ \\
\hline Baseline level & $9.28(2.39)$ & $9.29(2.46)$ & $0.932^{\text {ns }}$ \\
$1^{\text {st }}$ Follow up & $7.55(3.07)$ & $6.59(3.48)$ & $0.086^{\text {ns }}$ \\
(after 4 weeks) & & & \\
$2^{\text {nd } \text { Follow up }}$ & $4.72(2.80)$ & $3.48(2.20)$ & $0.024^{\mathrm{s}}$ \\
(after 8 weeks) & & & \\
\hline
\end{tabular}

$\mathrm{ns}=$ non-significant; $\mathrm{s}=$ significant

*Mann-Whitney U test was done to measure the level of significance.

Table V

\begin{tabular}{|c|c|c|c|}
\hline \multirow{2}{*}{$\begin{array}{l}\text { Duration of each } \\
\text { episode of } \\
\text { migraine (Hours) }\end{array}$} & \multicolumn{2}{|c|}{ Type of patients } & \multirow[t]{2}{*}{ p-value* } \\
\hline & $\begin{array}{c}\text { Group-I } \\
(\mathrm{n}=47) \\
\text { Mean (SD) }\end{array}$ & $\begin{array}{c}\text { Group-II } \\
(\mathrm{n}=49) \\
\text { Mean (SD) }\end{array}$ & \\
\hline Baseline level & $10.85(5.26)$ & $10.22(4.42)$ & $0.831^{\text {ns }}$ \\
\hline $\begin{array}{l}\text { st Follow up } \\
\text { after } 4 \text { weekss) }\end{array}$ & $8.06(4.11)$ & $6.97(2.47)$ & $0.344^{\mathrm{ns}}$ \\
\hline $\begin{array}{l}{ }^{\text {nd }} \text { Follow up } \\
\text { after } 8 \text { weekss) }\end{array}$ & $5.53(2.98)$ & $4.36(1.55)$ & $0.047^{\mathrm{s}}$ \\
\hline
\end{tabular}

$\mathrm{ns}=$ non-significant; $\mathrm{s}=$ significant

*Mann-Whitney U test was done to measure the level of significance.

Table-V shows that during $1^{\text {st }}$ follow up, statistically nonsignificant differences was observed but between groups there was more decreasing value in patients of group-II than that of group-I. During $2^{\text {nd }}$ follow up, statistical significant $(\mathrm{p}=0.047$ ) difference was observed in duration of migraine attack between group-I and group-II.

Table-VI shows that at baseline level, there was no statistical significant difference between group-I and group-II. During 1st follow up, patients were distributed in mild, moderate and severe groups but no statistical significant difference was found. In $2^{\text {nd }}$ follow up, patients had better condition and distributed in mild and moderate groups. There was statistical significant $(\mathrm{p}<0.05)$ difference between group-I and group-II.

\section{Table VI}

Severity of migraine based on categories of Visual Analogue Scale (VAS) in both groups

\begin{tabular}{|c|c|c|c|}
\hline \multirow{2}{*}{$\begin{array}{l}\text { Severity of } \\
\text { migraine }\end{array}$} & \multicolumn{2}{|c|}{ Type of patients } & \multirow[t]{2}{*}{$\mathrm{p}$-value* } \\
\hline & $\begin{array}{l}\text { Group-I } \\
(n=47)\end{array}$ & $\begin{array}{c}\text { Group-II } \\
(\mathrm{n}=49)\end{array}$ & \\
\hline \multicolumn{4}{|c|}{ Baseline level } \\
\hline Moderate & $25(53.2 \%)$ & $29(59.2 \%)$ & $0.700^{\mathrm{ns}}$ \\
\hline Severe & $22(46.8 \%)$ & $20(40.8 \%)$ & \\
\hline \multicolumn{4}{|c|}{$1^{\text {st Follow-up(after 4weeks) }}$} \\
\hline Mild & $24(51.1 \%)$ & $18(36.7 \%)$ & \\
\hline Moderate & $15(31.9 \%)$ & $21(42.9 \%)$ & $0.360^{\mathrm{ns}}$ \\
\hline Severe & $8(17.0 \%)$ & $10(20.4 \%)$ & \\
\hline \multicolumn{4}{|c|}{$2^{\text {nd }}$ Follow-up(after 8weeks) } \\
\hline Mild & $29(61.7 \%)$ & $40(81.6 \%)$ & $0.030^{\mathrm{s}}$ \\
\hline Moderate & $18(38.3 \%)$ & $9(18.4 \%)$ & \\
\hline
\end{tabular}

$\mathrm{ns}=$ non-significant; $\mathrm{s}=$ significant

*Chi square test was done to measure the level of significance

Table-VII shows distribution of patients according to adverse effects. In group- I, 23.4\% patients developed adverse effects and that of $14.3 \%$ in group-II. In group-I, $8.5 \%$ develop dizziness, drowsiness $6.3 \%$. On the other hand, in group-II, $6.1 \%$ developed bradycardia and $4.1 \%$ had drowsiness and generalized weakness. There was no statistical significant difference between both groups in terms of adverse effects.

Table VII

Adverse effects among study population

\begin{tabular}{|c|c|c|c|}
\hline \multirow[t]{2}{*}{ Adverse Effects } & \multicolumn{2}{|c|}{ Type of Patients } & \multirow{2}{*}{$\begin{array}{c}\mathrm{p}- \\
\text { value* }\end{array}$} \\
\hline & $\begin{array}{l}\text { Group-I } \\
(\mathrm{n}=47)\end{array}$ & $\begin{array}{c}\text { Group-II } \\
(\mathrm{n}=49)\end{array}$ & \\
\hline Yes & $11(23.4 \%)$ & $7(14.3 \%)$ & \\
\hline Dizziness & $4(8.5 \%)$ & $2(4.1 \%)$ & \\
\hline Drowsiness & $3(6.3 \%)$ & $0(0.0)$ & \\
\hline Blurring of vision & $2(4.2 \%)$ & $0(0.0)$ & $0.405^{\mathrm{ns}}$ \\
\hline Anorexia & $2(4.2 \%)$ & $0(0.0)$ & \\
\hline Bradycardia & $0(0.0)$ & $3(6.1 \%)$ & \\
\hline Generalized weakness & $0(0.0)$ & $2(4.1 \%)$ & \\
\hline No & $36(76.6 \%)$ & $42(85.7 \%)$ & \\
\hline
\end{tabular}

ns $=$ non-significant

*Chi-square test was done to measure the level of significance

\section{Discussion}

Various drugs have been used for migraine prophylaxis. In the present study, efficacy and safety of topiramate and 
propranolol were compared. Among the many different beta-blockers, propranolol is one of the most commonly prescribed for migraine prophylaxis ${ }^{12}$. Recently, antiepileptic drugs including topiramate (TPM) are more commonly used in adults and adolescents for migraine prophylaxis.

There are substantial number of study demonstrating the efficacy of topiramate and propranolol in the treatment of migraine ${ }^{13}$. It is one of the clinical trials of migraine to compare topiramate and propranolol in Bangladesh context. We compared our study findings with result of some other published articles elsewhere in the world.

Analysis of age distribution showed that, the mean age was found $29.72 \pm 9.58$ years in group-I and mean age were $30.96 \pm 10.11$ years in group-II but no significant difference in age distribution among both groups. A good number of the study patients were 18-25 years age group in both groups (42.6\% vs. $42.9 \%$ ). A study done by Dahlöf et al. $(2007)^{14}$ found mean (SD) age, 39.8 years who studied on topiramate placebo-controlled clinical trials. In this study, patients were younger than the patients of above mentioned studies.

Out of all patients in group-I, $72.3 \%$ was female and $27.7 \%$ male. In group-II, $61.2 \%$ was female and $38.8 \%$ male. No statistically significant difference was observed between groups in terms of gender $(\mathrm{P}>0.05)$. Diener et al. $(2004)^{15}$ and Brandes et al. (2004) ${ }^{9}$ also found more female patients of migraine $76 \%$ and $82 \%$, respectively. These results are almost similar to our study.

Out of all patients, $16(16.7 \%)$ patients had migraine with aura. Among them, 7 patients in group-I and 9 patients in group-II declared to have aura. But there was no statistical significant difference between group-I and group-II in consideration of migraine with aura (14.9\% vs. $18.4 \%$, p value $>0.05$ ).

The efficacy of prophylactic drug, based on frequency of migraine attack was seen in both groups individually. During $2^{\text {nd }}$ follow up, there was statistically significant difference in mean (SD) value of frequency of migraine attack between group-I and group-II ( $4.72 \pm 2.80$ vs. 3.48 $\pm 2.20 ; p=0.024]$. It signifies that a significant decreasing trend of level of frequency in group-II than that of groupI especially in $2^{\text {nd }}$ follow up So, this present study showed better reduction of headache intensity in propranolol group than topiramate group. Ashtari et al. $(2008)^{13}$ found that the topiramate group showed more reduction in migraine frequency than propranolol group. These results are not similar to this study probably due to racial variation.
The efficacy of two drugs based on duration of each episode of migraine was seen in both groups, at final follow up there was statistically significant difference in mean (SD) value of duration of migraine attack between groupI and group-II ( $5.53 \pm 2.98$ vs. $4.36 \pm 1.55 ; \mathrm{p}=0.047)$. So, this present study showed better reduction of headache duration in propranolol group than topiramate group. Ashtari et al. (2008) ${ }^{13}$ found, headache duration decreased more in topiramate group than propranolol group.

According to VAS score patients were divided into mild, moderate and severe group. At baseline level, patients were distributed into moderate and severe groups .During 1 st follow up, patients was distributed in all mild, moderate and severe groups. At the end of the trial $2^{\text {nd }}$ follow up, patients had better condition and distributed in mild and moderate group. There was statistical significant difference between group-I and group-II (Mild: $61.7 \%$ vs. $81.6 \%$; Moderate: $38.3 \%$ vs. $18.4 \%$; $<<0.05$ ). So, this present study showed better reduction of headache intensity in propranolol group than topiramate group. Ashtari et al. $(2008)^{13}$ measured headache intensity lessened more in topiramate group than propranolol group. A study carried out by Bengt et al. (1976) ${ }^{16}$ found that propranolol was significantly better in reducing the intensity $\&$ duration of attack of migraine

Regarding adverse effects, in group-I, 23.4\% patients developed adverse effects and $14.3 \%$ in group-II. Among the adverse effects of group-I, $8.5 \%$ develop dizziness that was followed by drowsiness $6.3 \%$. On the other hand, in group-II, $6.1 \%$ developed bradycardia and $4.1 \%$ had dizziness and generalized weakness. There was no statistical significant difference between both groups in terms of adverse effects. Adverse effects of topiramate is $16 \%$ in the study of Silberstein et al. $(2012)^{8}$ which was relatively similar with the present study. Similar adverse effects of propranolol is found in the study of Gray et al. $(2004)^{17}$.

In present study, efficacy and adverse effect of topiramate and propranolol were compared and results showed that both drugs were effective in reduction of frequency, duration and severity of headache but propranolol was more effective than topiramate. Furthermore, in topiramate group, patients complained of more adverse effects than propranolol group (23.4\% vs. $14.3 \%)$. So, comparative studies of propranolol with topiramate showed that topiramate was more effective especially in Iran (Ashtari et al. 2008) ${ }^{13}$ but present study showed that, propranolol is more effective than topiramate in migraine prophylaxis probably due to poor metabolism of propranolol in our regional context (Correia, 2009) ${ }^{18}$. 


\section{Conclusion}

Considering statistical analyses, topiramate and propranolol both are individually safe and effective for migraine prophylaxis in reduction of frequency, severity and duration of migraine. But propranolol is more effective than topiramate in respect of reducing frequency, severity and duration of migraine.

\section{References}

1. Goadsby PJ, Raskin NH. Headache. In: Fauci AS, Braunwald E, Kasper DL, Hauser SL, Longo DL., Jameson JL. Harrison's Principles of Internal Medicine. $18^{\text {th }}$ ed. New York: McGrawHill; 2012. p.112-128

2. Silberstein SD. 'Preventive migraine treatment'. Neurol Clin 2009; 27(2): 429-43.

3. Olesen J. 'The international classification of headache disorders. $3^{\text {rd }}$ edition (ICHD-3)'. Cephalalgia 2013; 36(1): $1-16$

4. World Health Organization (WHO) (2001) The World Health Report 2001: Mental health, new understanding new hope. World Health Organization, Geneva, Switzerland. (www.who.int/whr/2001/main/en/overview/outline.htm) (accessed on October 30, 2015)

5. Leonardi M, Steiner TJ, Scher AT, Lipton RB. 'The global burden of migraine: measuring disability in headache disorders with WHO's Classification of Functioning, Disability and Health (ICF)'. Journal of Headache Pain 2005; 6(6): 429-40.

6. Lipton RB, Stewart WF, Diamond S, Diamond ML, Reed M. 'Prevalence and burden of migraine in the United States: data from the American Migraine Study II'. Headache 2001; 41(7): 646-57.

7. Hannan MA, Hasan MK, Begum A, Haque A, Anwarullah AKM, Khan MRK, Islam MR, Rahman HZ, Bhuiyan MM, Rizvi AN, Sarker DK. 'Study of epidemiological features of primary headache patients in a tertiary centre in Bangladesh'. Bangladesh Journal of Neuroscience 2007; 23(1): 11-22.

8. Silberstein SD, Dodick DW, Lindblad AS, Holoroyd K, Harrington M . 'Randomized,placebo-controlled trail of propranolol added to topiramate in chronic migraine'. Neurology 2012; 78:976-84.
9. Brandes JL, Saper JR, Diamond M. 'Topiramate for migraine prevention: a randomized controlled trial'. JAMA 2004; 291:965-73.

10. Al-Qassab HK, Findley LJ. (1993) 'Comparison of propranolol LA $80 \mathrm{mg}$ and propranolol LA $160 \mathrm{mg}$ in migraine prophylaxis: a placebo controlled study' Cephalalgia, 13: 128-31.

11. Chowdhury MI, Anwarullah AKM, Omar KM, Majumder S. (2012) 'Study on propranolol vs sodium valproate in the prevention of migraine.' Journal of Armed Forces Medical College of Bangladesh, 8: 32-8.

12. Ramadan NM, Silberstein SD, Freitag FG and Gilbert TT. (1999) 'Evidence-based guidelines of the pharmacological management for prevention of migraine for the primary care provider'. Available at: http:// www.neurology.org (accessed October 22, 2015).

13. Ashtari F, Shaygannejad V, Akbari M. 'A double-blind, randomized trial of low-dose topiramate vs propranolol in migraine prophylaxis' Acta Neurol Scand 2008;118:301-5.

14. Dahlöf C, Elizabeth L, Merle D, Marcia R, George P. 'The impact of migraine prevention on daily activities: a longitudinal and responder analysis from three topiramate placebo-controlled clinical trials' Health and Quality of Life Outcomes 2007;5:56 .Available at:www.hqlo.com/content/ 5/1/56 (accessed on October 30, 2015)

15. Diener HC, Tfelt-Hansen P, Dahlof C, Lainez MJ, Sandrini G. 'Topiramate in migraine prophylaxis - results from a placebo- controlled trial with propranolol as an active control'. J Neurol 2004 ; 251: 943-5.

16. Bengt F, Henriksson KG, Valur J, Lars L, Hakan L. (1976) 'Propranolol for migraine prophylaxis.' Headache, 16 : 23845.

17. Gray RN, Goslin RE, McCrory DC., Eberlein K, Tulsky J, Hasselblad V. (1999) 'Drug treatments for the prevention of migraine headache'. Prepared for the Agency for Health Care Policy and Research under Contract No. 290-94-2025. Available at: http://www.clinpol.mc.duke.edu (accessed on October 28, 2015)

18. Correia MA. (2009) 'Drug Biotransformation' In: Katzung BG, Masters SB, Trevor AJ. (eds). Basic and Clinical Pharmacology. $11^{\text {th }}$ ed, New York: McGraw-Hill. 